Article

\title{
Species-Dependent Functionality of the Human Cytolytic Fusion Proteins Granzyme B-H22(scFv) and H22(scFv)-Angiogenin in Macrophages
}

Sonja Schiffer ${ }^{1,2, \dagger}$, Dmitrij Hristodorov ${ }^{1, \dagger}$, Radoslav Mladenov ${ }^{1}$, Eric Aslanian ${ }^{1}$, Michael Huhn ${ }^{1}$, Rainer Fischer ${ }^{1,3}$, Stefan Barth ${ }^{1,2, \dagger}$ and Theo Thepen ${ }^{2, \dagger, *}$

1 Department of Experimental Medicine and Immunotherapy, Institute of Applied Medical Engineering, University Hospital RWTH Aachen, Aachen 52074, Germany

2 Department of Pharmaceutical Product Development, Fraunhofer Institute for Molecular Biology and Applied Ecology (IME), Aachen 52074, Germany

3 Institute of Molecular Biotechnology (Biology VII), RWTH Aachen University, Aachen 52074, Germany

$\dagger$ These authors contributed equally to the work.

* Author to whom correspondence should be addressed; E-Mail: thepen@ime.fraunhofer.de; Tel.: +49-241-6085-11131; Fax: +49-241-6085-10000.

Received: 5 December 2012; in revised form: 4 January 2013 / Accepted: 8 January 2013 / Published: 11 January 2013

Abstract: Human cytolytic fusion proteins (hCFPs) are comprised of a specific cell-surface-binding moiety and an effector molecule of human origin. In contrast to common immunotoxins, including bacterial or plant toxins, they are considered not to be immunogenic. Two examples for human pro-apoptotic effector proteins are the serine protease Granzyme B and the RNase Angiogenin. Pre-clinical testing of functionality in in vitro and in vivo studies is essential for therapeutics. Establishing relevant animal models that have predictive value for therapeutic success is a great challenge in biomedical research. In this study, we investigated the species-dependent cytotoxic activity of two hCFPs prior to their application in a murine inflammation model. We found that in vitro and ex vivo either hCFP was able to kill human cells only, leaving murine cells unaffected. In contrast, no species-dependency was found for the bacterial Pseudomonas exotoxin A based immunotoxin H22(scFv)-ETA'. This species-dependent functioning has to be carefully considered when performing pre-clinical studies in animal models. 
Keywords: immunotoxin; CD64; inflammation; mouse model

\section{Introduction}

The main problem of most standard therapeutic approaches against cancer or inflammatory diseases is their lack in specificity, which can lead to serious side effects. In order to circumvent this, more specific approaches are subject of current research. Among these are the common immunotoxins, which specifically deliver toxic components into diseased target cells $[1,2]$. These chimeric proteins contain a specific cell-binding moiety, which can either be a ligand, a full-length antibody, or a fragment thereof, coupled to an apoptosis-inducing molecule [3-6]. After binding to the target cell, the immunotoxin is internalized followed by endosomal processing and final release of the toxin into the cytosol, where it catalytically induces cell death [7]. The most frequently used toxins in these immunotherapeutic agents originate from plants, like Ricin A, or bacteria, like Pseudomonas exotoxin A (ETA) and Diphtheria Toxin [5,8-10]. A panel of those proteins, especially targeted against cancer cells, has already been investigated in clinical trials [11-13]. However, a major drawback of non-human toxins is the potential induction of unwanted immune responses [14]. This can limit the number of doses a patient can receive. A promising approach to overcome this problem is the use of fully human cytolytic fusion proteins (hCFPs). The most promising candidates being investigated are the enzymes Granzyme B and Angiogenin. Granzyme B, a serine proteinase mainly expressed in cytotoxic T lymphocytes or natural killer cells, is one of the most prominent initiator of apoptosis in the innate immune system [15]. Its apoptotic activity comprises both caspase-dependent and -independent pathways, and is based on the proteolytic cleavage of several downstream caspases like pro-caspase 3. Granzyme B can also directly cleave caspase substrates as well as caspase-independent proteins like Bid leading to the release of cytochrome $\mathrm{c}$ and mitochondrial permeability [16-19].

Human Angiogenin is a human plasma protein with 65\% homology to RNase A and is one of more than 20 ribonucleases involved in RNA metabolism [20]. In contrast to several other RNase A superfamily members, Angiogenin has been shown to be a potent inhibitor on protein synthesis through digestion of tRNA in cell-free systems [21].

Both enzymes have already been tested as cytolytic component in fusion proteins [22-26]. Examples are the CD64-specific hCFPs Granzyme B-H22(scFv) and H22(scFv)-Angiogenin which have previously been reported to specifically kill the human pro-monocytic leukemia cell line U937 in vitro [26,27]. This cancer cell line can be deployed in a murine acute myeloid leukemia xenograft tumor model [28], thus allowing for in vivo pre-clinical testing of new hCD64-targeting therapeutics. The contribution of the animal itself in such model is very limited. For other induced disease specific animal models the influence of the animal is much more significant, as the target cells are not transplanted xenografts, but the animal cells. To test novel therapeutics, transgenic animals are a potential solution. Here, the human target molecule is expressed by the animal cells and this allows for direct testing of the therapeutic agent. We have for instance employed hCD64 transgenic animals to that aim. We used them in several induced disease models, e.g., chronic cutaneous inflammation and arthritis [29,30]. Testing of a genetically engineered protein, H22-ETA', proved effective in 
eliminating inflammatory macrophages in the skin [31] in this model and resolution of the inflammation. When using human enzymes however, it has to be considered that they generally have a high specificity for their substrate, which may even be species-dependent so that on the animal substrate they may be less- or even in-effective. This might have serious consequences when testing human therapeutics for their specific and also unspecific toxicity in vivo.

In this study, we for the first time show that the two hCFPs, Granzyme B-H22(scFv) and $\mathrm{H} 22(\mathrm{scFv})$-Angiogenin, successfully kill human activated macrophages but fail to eliminate murine ones. This is in great contrast to H22(scFv)-ETA' [28,32], which induces apoptosis species-independently. Hence, we conclude that species-dependent functionality of human immunotherapeutics has to be taken into account when testing new candidates in pre-clinical animal models.

\section{Results and Discussion}

The development of biological therapeutics moves strongly into the direction of human or humanized molecules. This introduces an additional problem, as the effector function of the therapeutic to be tested in such a model is a human enzyme. We developed several of those hCFP like Granzyme B-H22(scFv) and H22(scFv)-Angiogenin.

To investigate the feasibility of evaluating hCFPs in animal models other than cancer models (e.g., inflammation models), we first performed cytotoxicity assays with the murine B cell/macrophage cell line IIA1.6, which was transfected with hCD64 (hCD64 $\left.{ }^{+}\right)$. Non-transfected (hCD64) IIA1.6 cells and the original immunotoxin H22(scFv)-ETA' were used as controls. Although all tested proteins showed specific binding to hCD64 (Figure 1a), no cytotoxicity could be observed for the hCFPs Granzyme B-H22(scFv) or H22(scFv)-Angiogenin (Figure 1b). In contrast, the bacterial toxin ETA' showed hCD64-mediated cytotoxicity in a dose-dependent fashion resulting in an $\mathrm{IC}_{50}$ value of $13 \mathrm{nM}$. This result is in sharp contrast to the in vitro data obtained for the human CD64 ${ }^{+}$cell line U937 as previously described and establishes, for the first time, a species-dependent function of the two human effector proteins Granzyme B and Angiogenin.

To further confirm these data, we compared the cytotoxic potential of both fusion proteins ex vivo against $\mathrm{hCD} 4^{+}$primary macrophages macrophages. For the first time, we here demonstrate that Granzyme B and Angiogenin cannot only efficiently kill cancer cells but also human PBMC-derived macrophages. However, even though both hCFPs could specifically bind to the target receptor speciesindependently as demonstrated by flow cytometry (Figure 2a), neither Granzyme B-H22(scFv) nor $\mathrm{H} 22(\mathrm{scFv}$ )-Angiogenin could kill peritoneal mouse macrophages. This supports our hypothesis that human Granzyme B and Angiogenin act, in the context of hCFPs, in a species-specific manner. In agreement with the data obtained for the cell lines IIA1.6 and U937, the control immunotoxin $\mathrm{H} 22$ (scFv)-ETA' was able to kill both murine and human primary macrophages. Intriguingly, despite the universal efficacy of the chimeric H22(scFv)-ETA', it was less toxic $\left(\mathrm{IC}_{50}: 214 \mathrm{pM}\right)$ to human macrophages compared to both human cytolytic fusion proteins Granzyme B-H22(scFv) ( $\left.\mathrm{IC}_{50}: 108 \mathrm{pM}\right)$ and $\mathrm{H} 22(\mathrm{scFv})$-Ang ( $\left.\mathrm{IC}_{50}: 140 \mathrm{pM}\right)$. 
Figure 1. Binding (a) and cellular cytotoxicity (b) of $\mathrm{H} 22(\mathrm{scFv})$-based fusion proteins to the murine cell line IIA1.6. Cell binding activity of $1 \mu \mathrm{M}$ recombinant protein was analyzed by flow cytometry. Detection was performed using an anti-Penta-His-Alexa Fluor 488 antibody. Cellular cytotoxicity was assessed by a XTT assay. The concentration required to achieve $50 \%$ reduction of protein synthesis $\left(\mathrm{IC}_{50}\right)$ relative to untreated control cells was calculated using GraphPad Prism. All experiments were carried out in triplicates.

(a)

$-\mathrm{PBS} \quad-\mathrm{H} 22(\mathrm{scFv})-\mathrm{X}+$ anti-His-Alexa488

- anti-His-Alexa488
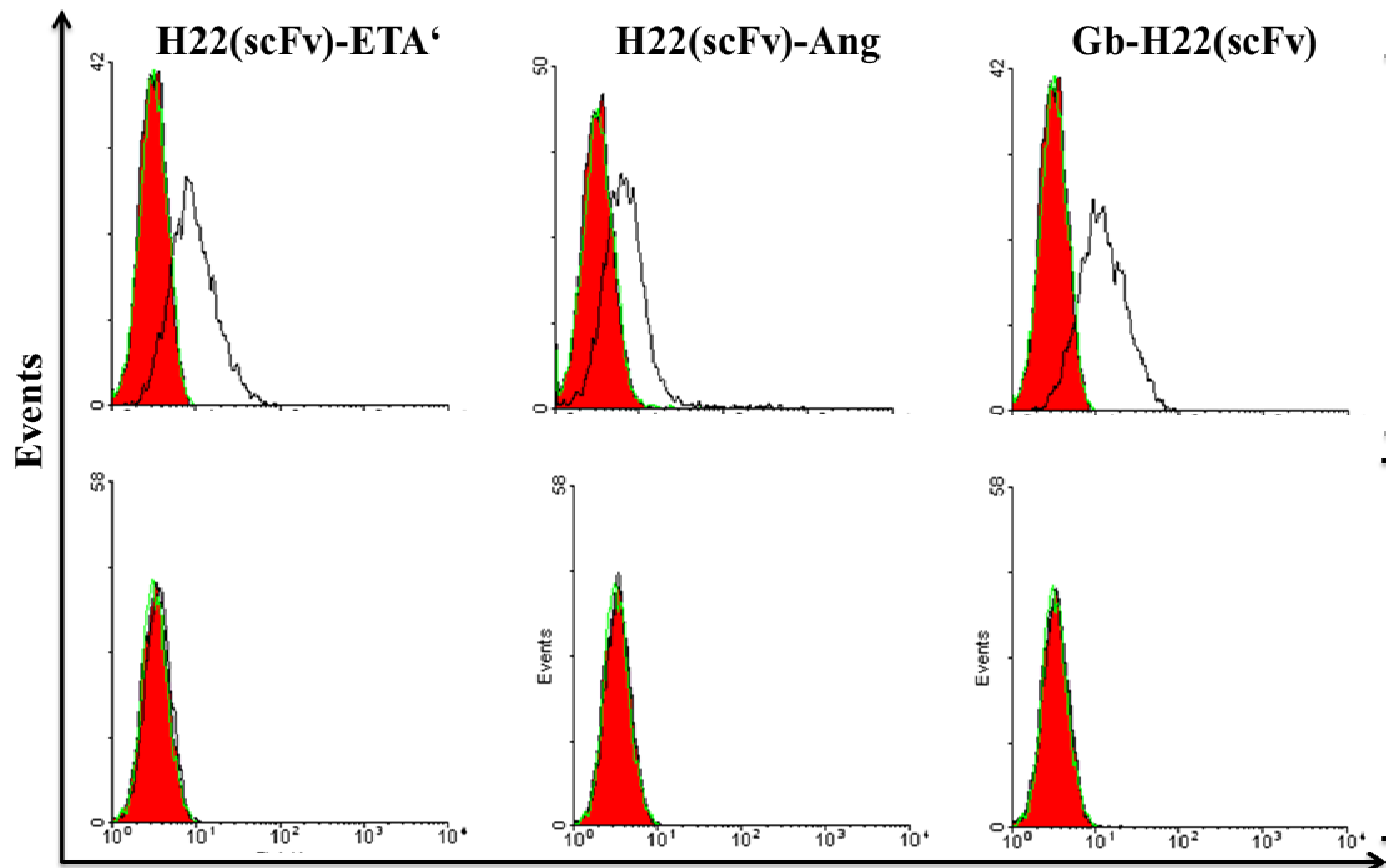

IIA1.6_hCD64 ${ }^{+}$
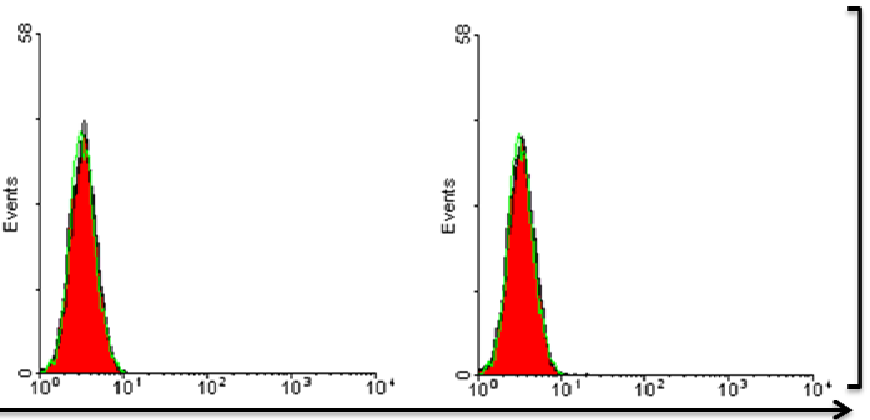

IIA1.6_hCD64-

CD64 expression

(b)
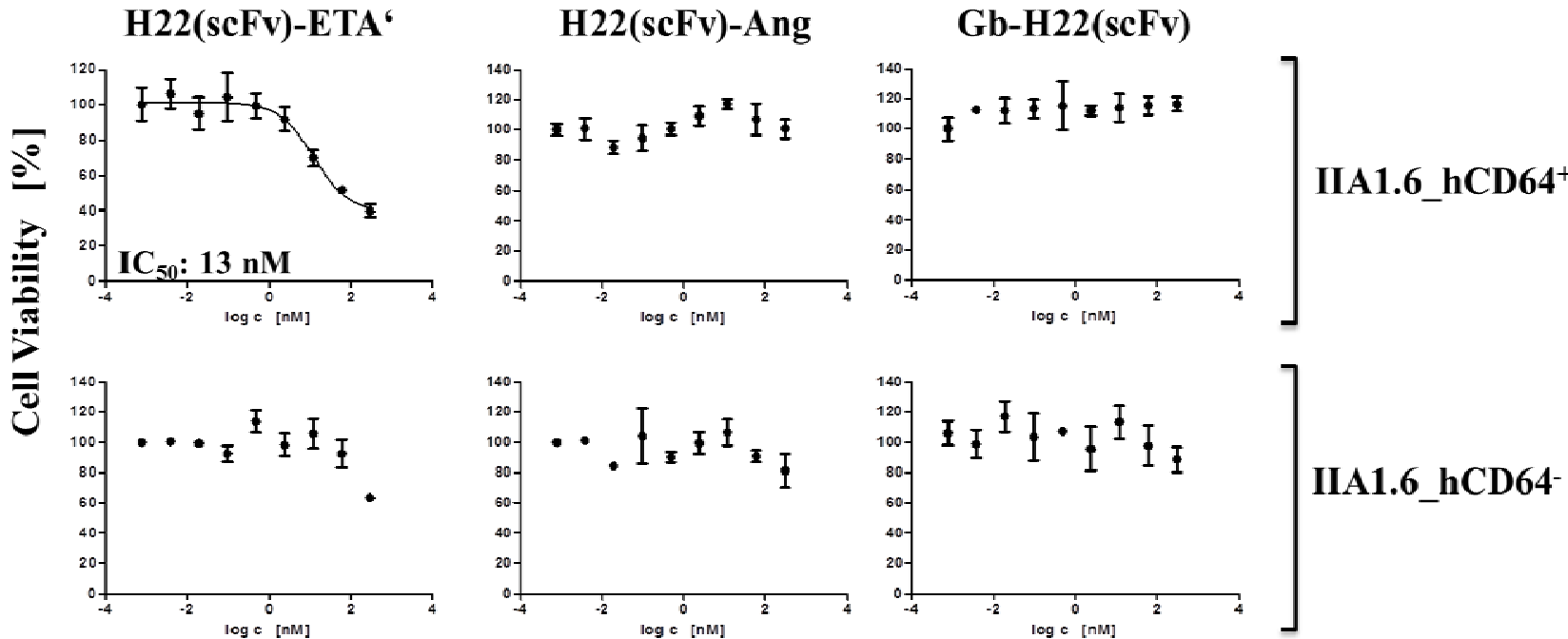

IIA1.6_hCD64- 
Figure 2. Binding (a) and cellular cytotoxicity (b) of $\mathrm{H} 22(\mathrm{scFv})$-based fusion proteins to hCD64-transgenic murine macrophages and human PBMCs-derived macrophages. Cell binding activity of $1 \mu \mathrm{M}$ recombinant protein was analyzed by flow cytometry. Detection was performed using an anti-Penta-His-Alexa Fluor 488 antibody. Cellular cytotoxicity was assessed by a XTT assay. The concentration required to achieve $50 \%$ reduction of protein synthesis $\left(\mathrm{IC}_{50}\right)$ relative to untreated control cells was calculated using GraphPad Prism. All experiments were carried out in triplicates.

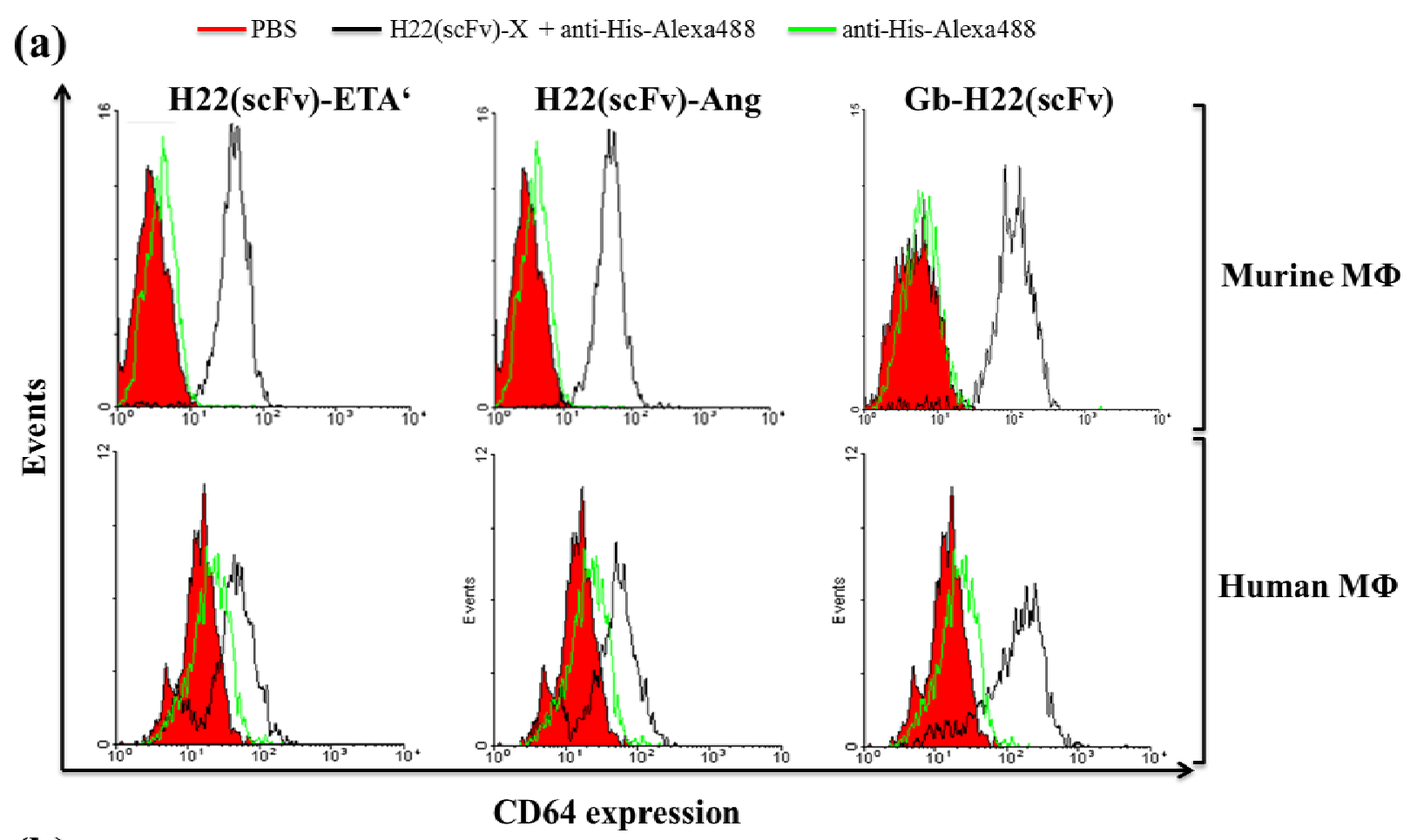

(b)
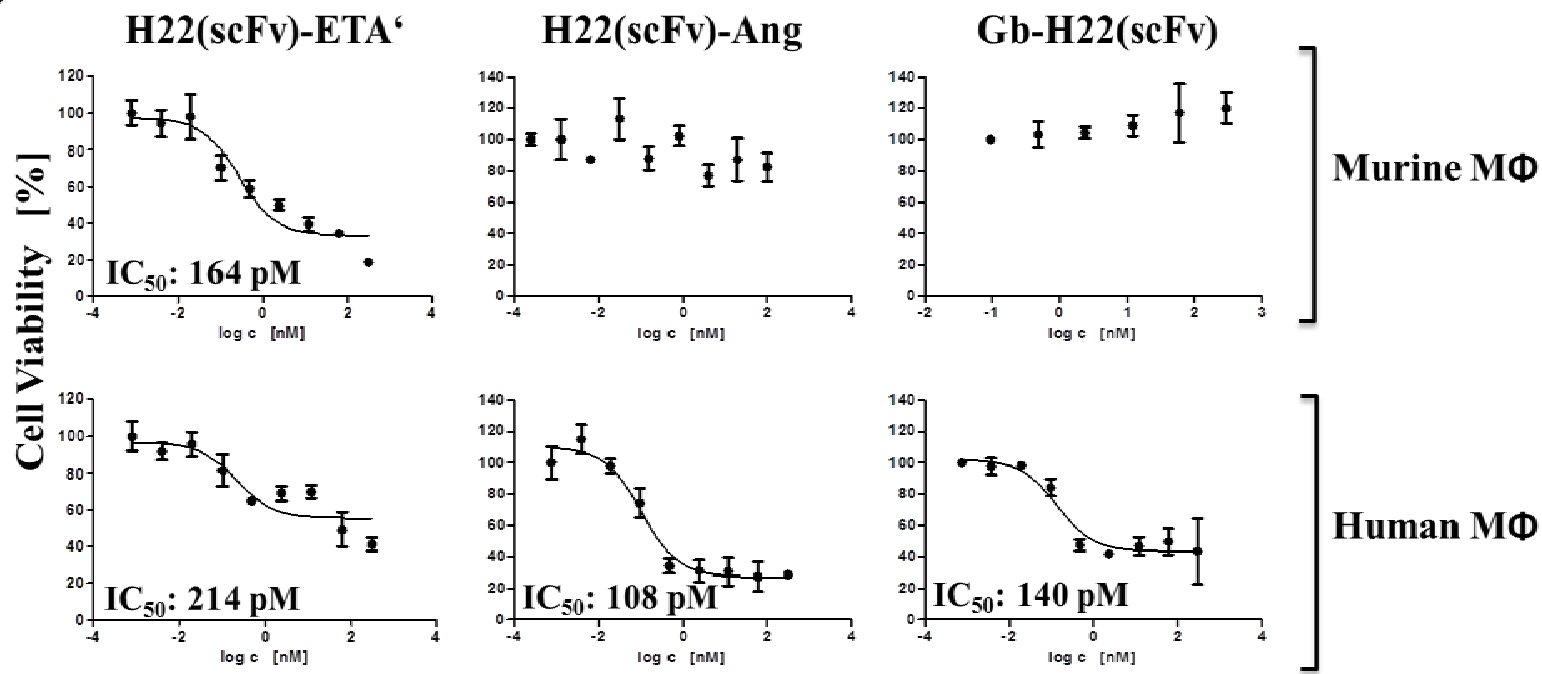

Species-dependent activity of human Granzyme B has been suggested previously. In contrast to our findings, in this study it was shown that human Granzyme B is able to kill several murine cell lines, such as C26 and LR7 [33] or P815 and EL4 [34]. However, here, the delivery of the enzyme into the cytosol was mediated by Streptolysin O (SLO) and not by receptor-mediated endocytosis, as it was the case in our experiments. This means that at least one of the key substrates for induction of apoptosis by 
Granzyme B is present in both human and murine cells. However, different routing pathways triggered by direct (SLO) or indirect (receptor-mediated endocytosis) delivery might prevent Granzyme B to encounter this key substrate. In support of this hypothesis, it was shown before that there are indeed evolutionary differences of murine and human Granzyme B. These were shown to be different enzymes [35] with distinct structural and functional characteristics [34]. While both cleave similar protein substrates, clear differences in the ability of cleaving, e.g., BID, ICAD or caspase-8 [35], which might represent crucial key substrates. For Angiogenin, nothing is known in literature about species-dependent differences of its inhibitory effect on protein synthesis. Indeed, our results suggest that the effect of human Angiogenin is absent in murine cells.

In addition to species-dependent differences in apoptosis-triggering mechanisms, specific inhibitors have also to be considered. As an example, the main Granzyme B inhibitor Serpin B9 (PI-9) is expressed only in human cells and it is capable of inhibiting human Granzyme B only. As opposed to this, the structurally similar murine variant SPI-6 can inhibit both murine and human Granzyme B, even though its inhibitory effect on human Granzyme B is lower than the one of PI-9 [36]. Similar to the inhibition of Granzyme B by endogenous inhibitors, the cytotoxic performance of the human RNase Angiogenin can be regulated by the cytosolic RNase inhibitor, which was shown to efficiently bind to RNases and block their catalytic activity [20]. This might be regulated differently in mice and humans leading to diminished apoptotic effects.

\section{Experimental Section}

\subsection{Protein Expression and Purification}

H22(scFv)-ETA' was produced via periplasmic stress expression in Escherichia coli BL21 (DE3)according to Tur et al. [32]. Granzyme B-H22(scFv) and $\mathrm{H} 22(\mathrm{scFv})$-Angiogenin were transiently expressed in HEK293T cells and purified from supernatant as described previously [26,27]. All proteins were purified by immobilized metal-ion affinity chromatography using Ni-NTA Sepharose (Qiagen, Germany) and size exclusion chromatography against PBS (pH 7.4) with Bio-Prep SE-100 $\Lambda 7$ (Bio-Rad, Germany) columns according to the manufacturer's instructions.

\subsection{Isolation and in Vitro Stimulation of Macrophages}

Peritoneal macrophages were induced by intraperitoneal injection of $1 \mathrm{~mL} 2 \%$ BioGel P-100 (BioRad, Germany) in hCD64-transgenic mice. After 3 days, mice were sacrificed and macrophages were isolated by peritoneal lavage using $5 \mathrm{~mL}$ of cold PBS ( $\mathrm{pH} 7.4$ ). After lysis of red blood cells, macrophages were cultured at a concentration of $0.5-1.0 \times 10^{6}$ cells $/ \mathrm{mL}$ in RPMI1640 medium supplemented with $10 \%(\mathrm{v} / \mathrm{v})$ FCS and 1\% Pen/Strep in T75 tissue culture flasks for 2-4 h. Non-adherent cells were removed by washing with cold PBS and macrophages were detached by incubation with cold $0.5 \mathrm{mM}$ EDTA in PBS (pH 7.4) for $10 \mathrm{~min}$ on ice. Appropriate number of cells was then seeded into assay plates and incubated o/n. Next day, cells were stimulated with $100 \mathrm{U} / \mathrm{mL}$ IFN- $\gamma$ (Peprotech, Germany) and $1 \mu \mathrm{g} / \mathrm{mL}$ LPS (Sigma-Aldrich, Germany) for $24 \mathrm{~h}$ before usage in functional assays. 
Human monocytes were isolated from buffy coats by gradient centrifugation with Ficoll (VWR, Germany) and cultured $\mathrm{o} / \mathrm{n}$ at conditions described above. After addition of $100 \mathrm{U} / \mathrm{mL}$ IFN- $\gamma$ and $1 \mu \mathrm{g} / \mathrm{mL}$ LPS, cells were incubated for $72 \mathrm{~h}$. Finally, cells were boosted with $50 \mathrm{U} / \mathrm{mL}$ IFN- $\gamma$ for $24 \mathrm{~h}$ and used in functional assays.

\subsection{Binding Analysis via Flow Cytometry}

Cell binding activity of purified proteins was analyzed by flow cytometry. A total of $4 \times 10^{5}$ cells were incubated with $1 \mu \mathrm{M}$ of recombinant protein in PBS ( $\mathrm{pH} 7.4$ ) containing 2 mM EDTA and $0.5 \%$ BSA for 30 min on ice followed by washing with PBS. Fluorescence staining was performed using an anti-Penta-His-Alexa Fluor 488 antibody (1:100; Qiagen, Germany) for $30 \mathrm{~min}$ on ice in the dark. Finally, the cells were washed twice with PBS and subsequently analyzed on a FACS Calibur flow cytometer (Becton Dickinson).

\subsection{In Vitro Cellular Cytotoxicity}

The cytotoxic effect of recombinantly produced proteins towards hCD64 ${ }^{+}$cells (IIA1.6 transfected with hCD64, hCD64 transgenic murine peritoneal macrophages, and PBMCs-derived human macrophages) was assessed by measuring the conversion of XTT to a water-soluble orange formazan dye. Therefore, $5 \times 10^{5}$ cells/well were seeded into a 96-well microtiter plate and incubated with various dilutions of the recombinant protein for $72 \mathrm{~h}$ at $37{ }^{\circ} \mathrm{C}, 5 \% \mathrm{CO}_{2}$, and $100 \%$ humidity. Nontransfected IIA1.6 cells were used as control to exclude unspecific toxicity. For the read out of cell viability, $50 \mu \mathrm{L}$ of XTT/phenanzinemethosulfate (100:1; Serva and Sigma-Aldrich, Germany) solution were added to each well followed by incubation for 3-4 h. Absorbance $450-630 \mathrm{~nm}$ were measured using an Epoch Microplate Spectrophotometer (Biotek, Germany). The concentration required to achieve $50 \%$ reduction of protein synthesis $\left(\mathrm{IC}_{50}\right)$ relative to untreated control cells was calculated using GraphPad Prism (GraphPad Software, USA). All experiments were carried out in triplicates.

\section{Conclusions}

Collectively, our observations highlight the complexity and potential pitfalls of selecting and designing human immunotherapeutics such as proteases or RNases. Even though human Granzyme B was previously shown to kill both murine and human cancer cells, our results demonstrate a strongly species-dependent cytolytic function in primary macrophages. Additionally, we could further confirm species-dependent cytotoxicity of hCFPs by testing the human RNase Angiogenin, which, in contrast to human macrophages, also failed to induce apoptosis in murine ones. Finally, our results raise the question, whether and how human therapeutics can be pre-clinically tested for their specific and unspecific toxicity in vivo using an animal model for macrophage-related diseases.

\section{Acknowledgments}

We thank Reinhard Rosinke and Christian Cremer for providing H22(scFv)-ETA' and H22(scFv)Angiogenin, respectively. Reinhard Rosinke is also acknowledged for preparation of PBMCs-derived monocytes from buffy coats. 


\section{References and Notes}

1. Kreitman, R.J. Recombinant toxins for the treatment of cancer. Curr. Opin. Mol. Ther. 2003, 5, $44-51$.

2. Allen, T.M. Ligand-targeted therapeutics in anticancer therapy. Nat. Rev. Cancer 2002, 2, 750-763.

3. Cawley, D.B.; Herschman, H.R.; Gilliland, D.G.; Collier, R.J. Epidermal growth factor-toxin A chain conjugates: EGF-ricin $\mathrm{A}$ is a potent toxin while EGF-diphtheria fragment $\mathrm{A}$ is nontoxic. Cell 1980, 22, 563-570.

4. Williams, D.P.; Parker, K.; Bacha, P.; Bishai, W.; Borowski, M.; Genbauffe, F.; Strom, T.B.; Murphy, J.R. Diphtheria toxin receptor binding domain substitution with interleukin-2: Genetic construction and properties of a diphtheria toxin-related interleukin-2 fusion protein. Protein Eng. 1987, 1, 493-498.

5. Zhou, X.X.; Ji, F.; Zhao, J.L.; Cheng, L.F.; Xu, C.F. Anti-cancer activity of anti-p185HER-2 ricin A chain immunotoxin on gastric cancer cells. J. Gastroenterol. Hepatol. 2010, 25, 1266-1275.

6. Hu, C.C.; Ji, H.M.; Chen, S.L.; Zhang, H.W.; Wang, B.Q.; Zhou, L.Y.; Zhang, Z.P.; Sun, X.L.; Chen, Z.Z.; Cai, Y.Q.; et al. Investigation of a plasmid containing a novel immunotoxin VEGF165-PE38 gene for antiangiogenic therapy in a malignant glioma model. Int. J. Cancer 2010, 127, 2222-2229.

7. Hristodorov, D.; Mladenov, R.; Huhn, M.; Barth, S.; Thepen, T. Macrophage-targeted therapy: CD64-based immunotoxins for treatment of chronic inflammatory diseases. Toxins 2012, 4 , 676-694.

8. Barta, S.K.; Zou, Y.; Schindler, J.; Shenoy, N.; Bhagat, T.D.; Steidl, U.; Verma, A. Synergy of sequential administration of a deglycosylated ricin A chain-containing combined anti-CD19 and anti-CD22 immunotoxin (Combotox) and cytarabine in a murine model of advanced acute lymphoblastic leukemia. Leukemia Lymphoma 2012, 53, 1999-2003.

9. Schnell, R.; Vitetta, E.; Schindler, J.; Borchmann, P.; Barth, S.; Ghetie, V.; Hell, K.; Drillich, S.; Diehl, V.; Engert, A. Treatment of refractory Hodgkin's lymphoma patients with an anti-CD25 ricin A-chain immunotoxin. Leukemia 2000, 14, 129-135.

10. Pai, L.H.; Pastan, I. Clinical trials with Pseudomonas exotoxin immunotoxins. Curr. Top. Microbiol. Immunol. 1998, 234, 83-96.

11. Frankel, A.E.; Powell, B.L.; Hall, P.D.; Case, L.D.; Kreitman, R.J. Phase I trial of a novel diphtheria toxin/granulocyte macrophage colony-stimulating factor fusion protein (DT388GMCSF) for refractory or relapsed acute myeloid leukemia. Clin. Cancer Res. 2002, 8, 1004-1013.

12. Furman, R.R.; Grossbard, M.L.; Johnson, J.L.; Pecora, A.L.; Cassileth, P.A.; Jung, S.H.; Peterson, B.A.; Nadler, L.M.; Freedman, A.; Bayer, R.L.; et al. A phase III study of anti-B4-blocked ricin as adjuvant therapy post-autologous bone marrow transplant: CALGB 9254. Leukemia Lymphoma 2011, 52, 587-596.

13. Kreitman, R.J.; Tallman, M.S.; Robak, T.; Coutre, S.; Wilson, W.H.; Stetler-Stevenson, M.; Fitzgerald, D.J.; Lechleider, R.; Pastan, I. Phase I trial of anti-CD22 recombinant immunotoxin moxetumomab pasudotox (CAT-8015 or HA22) in patients with hairy cell leukemia. J. Clin. Oncol. 2012, 30, 1822-1828. 
14. Mathew, M.; Verma, R.S. Humanized immunotoxins: A new generation of immunotoxins for targeted cancer therapy. Cancer Sci. 2009, 100, 1359-1365.

15. Trapani, J.A. Granzymes: A family of lymphocyte granule serine proteases. Genome Biol. 2001, 2, REVIEWS3014.

16. Metkar, S.S.; Wang, B.; Ebbs, M.L.; Kim, J.H.; Lee, Y.J.; Raja, S.M.; Froelich, C.J. Granzyme B activates procaspase-3 which signals a mitochondrial amplification loop for maximal apoptosis. J. Cell Biol. 2003, 160, 875-885.

17. Trapani, J.A.; Jans, P.; Smyth, M.J.; Froelich, C.J.; Williams, E.A.; Sutton, V.R.; Jans, D.A. Perforin-dependent nuclear entry of granzyme B precedes apoptosis, and is not a consequence of nuclear membrane dysfunction. Cell Death Differ. 1998, 5, 488-496.

18. Barry, M.; Heibein, J.A.; Pinkoski, M.J.; Lee, S.F.; Moyer, R.W.; Green, D.R.; Bleackley, R.C. Granzyme B short-circuits the need for caspase 8 activity during granule-mediated cytotoxic T-lymphocyte killing by directly cleaving Bid. Mol. Cell. Biol. 2000, 20, 3781-3794.

19. Andrade, F.; Casciola-Rosen, L.A.; Rosen, A. Granzyme B-induced cell death. Acta Haematol. 2004, 111, 28-41.

20. Schirrmann, T.; Krauss, J.; Arndt, M.A.; Rybak, S.M.; Dubel, S. Targeted therapeutic RNases (ImmunoRNases). Expert Opin. Biol. Ther. 2009, 9,79-95.

21. Saxena, S.K.; Rybak, S.M.; Davey, R.T., Jr.; Youle, R.J.; Ackerman, E.J. Angiogenin is a cytotoxic, tRNA-specific ribonuclease in the RNase A superfamily. J. Biol. Chem. 1992, 267, 21982-21986.

22. Stahnke, B.; Thepen, T.; Stocker, M.; Rosinke, R.; Jost, E.; Fischer, R.; Tur, M.K.; Barth, S. Granzyme B-H22(scFv), a human immunotoxin targeting CD64 in acute myeloid leukemia of monocytic subtypes. Mol. Cancer Ther. 2008, 7, 2924-2932.

23. Huhn, M.; Sasse, S.; Tur, M.K.; Matthey, B.; Schinkothe, T.; Rybak, S.M.; Barth, S.; Engert, A. Human angiogenin fused to human CD30 ligand (Ang-CD30L) exhibits specific cytotoxicity against CD30-positive lymphoma. Cancer Res. 2001, 61, 8737-8742.

24. Liu, Y.; Cheung, L.H.; Hittelman, W.N.; Rosenblum, M.G. Targeted delivery of human pro-apoptotic enzymes to tumor cells: In vitro studies describing a novel class of recombinant highly cytotoxic agents. Mol. Cancer Ther. 2003, 2, 1341-1350.

25. Zhang, L.; Zhao, J.; Wang, T.; Yu, C.J.; Jia, L.T.; Duan, Y.Y.; Yao, L.B.; Chen, S.Y.; Yang, A.G. HER2-targeting recombinant protein with truncated pseudomonas exotoxin A translocation domain efficiently kills breast cancer cells. Cancer Biol. Ther. 2008, 7, 1226-1231.

26. Hetzel, C.; Bachran, C.; Fischer, R.; Fuchs, H.; Barth, S.; Stocker, M. Small cleavable adapters enhance the specific cytotoxicity of a humanized immunotoxin directed against CD64-positive cells. J. Immunother. 2008, 31, 370-376.

27. Stahnke, B.; Thepen, T.; Stocker, M.; Rosinke, R.; Jost, E.; Fischer, R.; Tur, M.K.; Barth, S. Granzyme B-H22(scFv), a human immunotoxin targeting CD64 in acute myeloid leukemia of monocytic subtypes. Mol. Cancer Ther. 2008, 7, 2924-2932.

28. Tur, M.K.; Huhn, M.; Jost, E.; Thepen, T.; Brummendorf, T.H.; Barth, S. In vivo efficacy of the recombinant anti-CD64 immunotoxin $\mathrm{H} 22(\mathrm{scFv})-\mathrm{ETA}^{\prime}$ in a human acute myeloid leukemia xenograft tumor model. Int. J. Cancer 2011, 129, 1277-1282. 
29. van Roon, J.A.; van Vuuren, A.J.; Wijngaarden, S.; Jacobs, K.M.; Bijlsma, J.W.; Lafeber, F.P.; Thepen, T.; van de Winkel, J.G. Selective elimination of synovial inflammatory macrophages in rheumatoid arthritis by an Fcgamma receptor I-directed immunotoxin. Arthrit. Rheum. 2003, 48, 1229-1238.

30. van Vuuren, A.J.; van Roon, J.A.; Walraven, V.; Stuij, I.; Harmsen, M.C.; McLaughlin, P.M.; van de Winkel, J.G.; Thepen, T. CD64-directed immunotoxin inhibits arthritis in a novel CD64 transgenic rat model. J. Immunol. 2006, 176, 5833-5838.

31. Ribbert, T.; Thepen, T.; Tur, M.K.; Fischer, R.; Huhn, M.; Barth, S. Recombinant, ETA'-based CD64 immunotoxins: improved efficacy by increased valency, both in vitro and in vivo in a chronic cutaneous inflammation model in human CD64 transgenic mice. Br. J. Dermatol. 2010, $163,279-286$.

32. Tur, M.K.; Huhn, M.; Thepen, T.; Stocker, M.; Krohn, R.; Vogel, S.; Jost, E.; Osieka, R.; van de Winkel, J.G.; Fischer, R.; et al. Recombinant CD64-specific single chain immunotoxin exhibits specific cytotoxicity against acute myeloid leukemia cells. Cancer Res. 2003, 63, 8414-8419.

33. de Poot, S.A.H.; Westgeest, M.; Hostetter, D.R.; Van Damme, P.; Plasman, K.; Demeyer, K.; Broekhuizen, R.; Gevaert, K.; Craik, C.S.; Bovenschen, N. Human and mouse granzyme M display divergent and species-specific substrate specificities. Biochem. J. 2011, 437, 431-442.

34. Kaiserman, D.; Bird, C.H.; Sun, J.R.; Matthews, A.; Ung, K.; Whisstock, J.C.; Thompson, P.E.; Trapani, J.A.; Bird, P.I. The major human and mouse granzymes are structurally and functionally divergent. J. Cell Biol. 2006, 175, 619-630.

35. Cullen, S.P.; Adrain, C.; Luthi, A.U.; Duriez, P.J.; Martin, S.J. Human and murine granzyme B exhibit divergent substrate preferences. J. Cell Biol. 2007, 176, 435-44.

36. Bots, M.; Van Bostelen, L.; Rademaker, M.T.; Offringa, R.; Medema, J.P. Serpins prevent granzyme-induced death in a species-specific manner. Immunol. Cell Biol. 2006, 84, 79-86.

(C) 2013 by the authors; licensee MDPI, Basel, Switzerland. This article is an open access article distributed under the terms and conditions of the Creative Commons Attribution license (http://creativecommons.org/licenses/by/3.0/). 